\title{
Effect of salts on the removal of remazol yellow by using activated charcoal prepared from sawdust
}

\author{
N. J. Ara ${ }^{1 *}$, M. A. Rahman ${ }^{2}$ And A. M. S. Alam ${ }^{2}$ \\ ${ }^{1}$ Department of Chemistry, Bangladesh University of Textiles-1208, Bangladesh. \\ ${ }^{2}$ Department of Chemistry, University of Dhaka-1000, Bangladesh.
}

\begin{abstract}
This study was to investigate the removal of Remazol Yellow dye from aqueous solutions by adsorption on activated charcoal prepared by chemical activation of saw dust. The dye removal was $85 \%$ which was increased to $94 \%$ with the addition of $1.0 \mathrm{~g}$ of $\mathrm{NaCl}$ electrolyte for 50 $\mathrm{mL}$ dye solution. The data were well fitted in Langmuir isotherm. The interactions were evaluated with respect to both pseudo-first-order and pseudo-second-order reaction kinetics. The adsorption process was found to follow the pseudo-second-order model. To optimize the operating conditions, the effect of $\mathrm{pH}$, temperature, adsorbent dosage, and initial dye concentration and initial volume of dye solutions were investigated. The obtained results indicated that the utilization of activated charcoal produced from saw dust played an important role in the removal of Remazol Yellow(RY) dye from aqueous solutions. In addition, saw dust was low cost and easily available material. It can be an alternative adsorbent precursor for more expensive adsorbents used for RY removal.
\end{abstract}

Keywords: Remazol yellow; Adsorption; Activated charcoal; Saw dust; Electrolyte

\section{Introduction}

Globally, thousands of dyes stuffs are being synthesized daily and also being released in the environment in the form of effluents during synthesis and dyeing process ${ }^{1}$. Reactive dyes are the most common dyes used due to their favorable characteristics of bright color, water fastness, simple application techniques, and low energy consumption. They exhibit a wide range of different chemical structures, primarily based on substituted aromatic and heterocyclic groups $^{2,3}$. They are not easily biodegradable, thus, the colour may remain in the effluent even after extensive treatment ${ }^{4,5}$. If waste products are improperly managed, public health and the environment could be threatened ${ }^{6,7}$.

To remove dyes and other contaminants from waste water, several physical, chemical and biological methods have been developed, such as membrane separation, flocculation coagulation, adsorption, ozonization and aerobic/anaerobic treatments ${ }^{8,9,10}$. However, these technologies are generally unsuccessful in colour removal, expensive, and less adaptable to a wide range of dye wastewaters ${ }^{11,12}$. The low cost, simple design, easy handling, and sludge-free cleaning operations have established the adsorption technique as more effective and convenient in comparison to other techniques ${ }^{13}$.

Adsorption now plays a key role in modern industries, mainly in the field of environmental protection engineering, with the increasing environmental consciousness of people all over the world. Adsorption processes are being employed widely for large scale biochemical, chemical, and environmental recovery and purification applications ${ }^{14}$. Over the last few decades, adsorption has been recognized as an influential separation process and has become an attractive option for the removal of dyes from industrial effluents ${ }^{15}$. Among various adsorbents, activated carbons are the most effective because of their excellent adsorption capacity for organic targets ${ }^{15}$. Many studies have been undertaken to investigate the use of low cost adsorbents such as peat, wood shavings, silica ${ }^{11,16-18,}$ coir pith ${ }^{19}$, sugar beet pulp ${ }^{20}$, sugar cane bagasse pith ${ }^{21}$, jute fiber ${ }^{22}$, soybean ${ }^{23}$, and wheat husk 24 for colour removal. Unfortunately, these low cost adsorbents have generally low adsorption capacities and require large amounts of adsorbents. Therefore, a need arises 
to find new, economical, easily available, and highly effective adsorbents ${ }^{11}$.

Wood industries in Bangladesh produce a lot of saw dust as by products. These byproducts are usually disposed of by burning or by deposition in landfills, but conversion to higher-value products would be preferable. One such product could be activated carbon. Previously, we have studied the

removal of Remazol Red with activated charcoal prepared from saw dust ${ }^{25}$. However, no information is available on removal of Remazol Yellow with activated charcoal prepared from saw dust. In this present research, the effects of salts on the removal of Remazol Yellow by activated charcoal prepared from saw dust was studied. Effects of various experimental parameters were investigated in batch mode to measure the adsorption rate. The isothermal data could be well described by the Langmuir and Freundlich isotherm. The kinetic data were well fitted to pseudo-second order model.

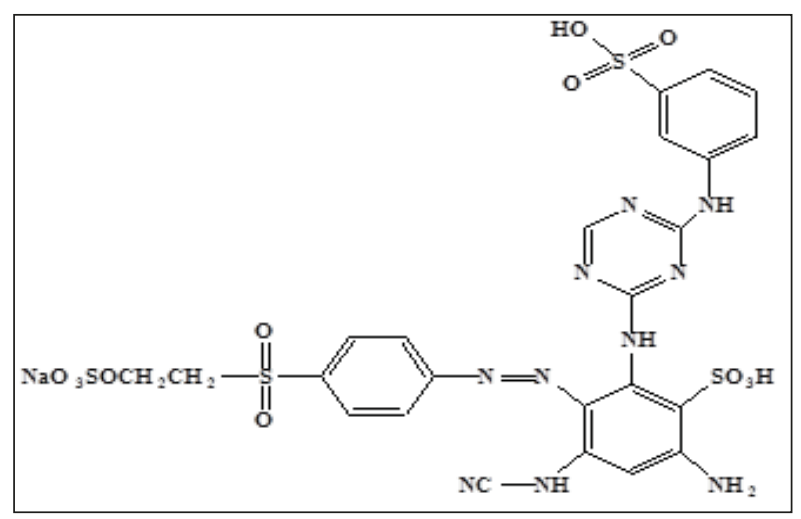

Fig. 1. Chemical structure of remazol yellow

\section{Experimental}

\section{Preparation of activated charcoal}

There are two different processes for the preparation of activated carbon: physical activation and chemical activation ${ }^{26}$.Saw dust was collected from nearby sources. This was washed with distilled water to remove water-soluble impurities and surface-adhered particles. Then, it was oven-dried at $60^{\circ} \mathrm{C}$ to remove the moisture and other volatile impurities. Then, part of the dried saw dust was soaked in concentrated $\mathrm{H}_{2} \mathrm{SO}_{4}$ in an amount sufficient to cover the raw material completely, agitated at $120 \mathrm{rpm}$ in an incubator shaker for $30 \mathrm{~min}$, and then left for $2 \mathrm{~h}$. After being mixed, the slurry was subjected to vacuum-drying at $100{ }^{\circ} \mathrm{C}$ for $24 \mathrm{~h}$. Chemical activation of the Saw dust was performed with
$\mathrm{ZnC1}_{2}$. Ten grams of Saw dust was well mixed with $100 \mathrm{ml}$ of a concentrated solution that contained $10 \mathrm{~g}$ of $\mathrm{ZnC1}_{2}$. The mixing was performed at $50{ }^{\circ} \mathrm{C}$ for $1 \mathrm{~h}$. After being mixed, the slurry was also be subjected to drying at $100{ }^{\circ} \mathrm{C}$ for $24 \mathrm{~h}^{27}$. The resulting impregnated solids were placed in a porcelain dish and heated $\left(5^{\circ} \mathrm{C} \mathrm{min}^{-1}\right)$ to a temperature of $300{ }^{\circ} \mathrm{C}$ for 1 h. After cooling, the products were washed sequentially with $0.5 \mathrm{~N} \mathrm{HCl}$, hot water, and finally cold distilled water to remove residual organic and mineral materials and then dried at $110^{\circ} \mathrm{C}$.

\section{Chemicals and dye solution}

Deionized water and high purity reagents were used for all standard and sample solution. Remazol Yellow(RY) was used in the experiment. RY, a reactive dye supplied by dye star Ltd., Dhaka, Bangladesh. This dye form a covalent bond with the fiber, usually cotton, although they are used to small extent on wool and nylon. This class of dyes first introduced commercially in 1956, made it possible to achieve extremely high washing fastness properties by relatively simple dyeing methods ${ }^{2}$. The chemical structure of dye is shown in Fig. 1. A stock solution of Remazol Yellow was prepared by dissolving the necessary amount of dye in water.

\section{Point of zero charge}

This is the point where the surface charge of adsorbent is zero. The point of zero charge $\left(\mathrm{pH}_{\mathrm{ZPC}}\right)$ for the sawdust was determined by the following procedure: $100 \mathrm{~mL}$ of deionized water was added to an Erlenmeyer flask, which was then capped with cotton. The deionized water was heated until boiling for $20 \mathrm{~min}$ to eliminate the $\mathrm{CO}_{2}$ and dissolved ions in the water. The $\mathrm{CO}_{2}$ free water was cooled as soon as possible, and the flask was immediately capped. Now this water is free from both cations and anions, and it is considered to be a neutral one. On the other hand, $0.5 \mathrm{~g}$ of activated carbon was weighed and placed in a $25 \mathrm{~mL}$ Erlenmeyer flask to which 10 $\mathrm{mL}$ of $\mathrm{CO}_{2}$ free deionized water was added. The flask was sealed with a rubber stopper and left in continuous agitation for $48 \mathrm{~h}$ at $25^{\circ} \mathrm{C}$. The $\mathrm{pH}$ of the solution was measured, and this value is the point of zero charge ${ }^{25}$.

\section{Study of batch adsorption process}

Equilibrium isotherms for adsorption onto the activated carbons determined by using $1 \mathrm{~g}$ of adsorbent per $50 \mathrm{ml}$ of aqueous solution for initial dye concentrations in the range of 50-200 ppm. For these experiments, the bottles were shaken at constant temperature $\left(25^{\circ} \mathrm{C}\right)$ with agitation speed $(120$ $\mathrm{rpm}$ ), for the minimum contact time required to attain equilibrium, as determined from the kinetic measurements. The effectiveness of the treatment was evaluated by 
measuring concentration by UV-Visible spectroscopic method at $590 \mathrm{~nm}$. The influence of $\mathrm{pH}$ was studied by adjusting the reaction mixture to different initial $\mathrm{pH}$ values and analyzing the residual color at the equilibrium contact time.

The $\mathrm{pH}$ values were adjusted with dilute sulfuric acid and sodium hydroxide solutions. Then the percentage of dye removal was calculated by,

$\mathrm{R}=\frac{\left(C_{o}-C_{e}\right)}{C_{o}} \times 100 \%$

The amount of dye adsorbed onto the activated carbons, $\mathrm{q}_{\mathrm{e}}$ (mg/g), was calculated according to:

$$
q_{e}=\frac{\left(C_{o}-C_{e}\right) V}{W}
$$

Where $\mathrm{C}_{0}$ and $\mathrm{C}_{\mathrm{e}}$ are the initial and the final dye concentrations $(\mathrm{mg} / \mathrm{L})$, respectively, and $\mathrm{W}$ is the amount of adsorbent $(\mathrm{g}), \mathrm{V}$ is the volume of the solution (L)

\section{Results and discussion}

\section{Effect of adsorbent dosage}

Adsorbent dosage is an important parameter for the adsorption process as it determines the capacity of an adsorbent for a given initial concentration of the adsorbate. The adsorption experiments were carried out at different solid/liquid ratios for $24 \mathrm{~h}$. At an initial dye concentration of $50 \mathrm{mg} / \mathrm{L}$ adsorption results obtained for various adsorbent dosages are given in Fig. 2.

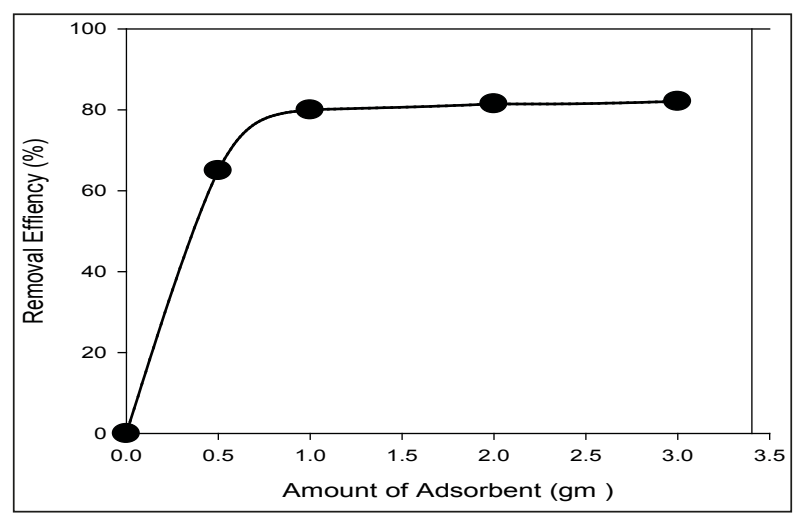

Fig. 2. Effect of adsorbent amount on the removal of remazol yellow.Particle size : $140 \mu \mathrm{m}$; Initial concentration: $50 \mathrm{mg} / \mathrm{L}$; Initial volume: $50 \mathrm{~mL}$; pH: 7.0; Contact time: 12 h; Temp.: $250 \mathrm{C}$
Fig. 2, shows that about $80 \%$ of dye was removed with $1.0 \mathrm{~g}$ of adsorbent. With increasing the amount of adsorbents (from $1.0 \mathrm{~g}$ to $3.0 \mathrm{~g}$ ) removal efficiency curve plateau was increased. However, 1.0, 2.0 and $3.0 \mathrm{~g}$ of adsorbent showed almost similar removal efficiency with same particle size of $<140 \mu \mathrm{m}$. This was due to the agglomeration of the particles themselves so that the removal efficiency was not significantly increased with amount of adsorbents. Therefore $1.0 \mathrm{~g}$ of adsorbent was chosen for the next experiment.

\section{Effect of contact time}

The adsorption of Remazol Yellow was studied as a function of contact time in order to determine the equilibrium time. The experiments were conducted at $25^{\circ} \mathrm{C}$ in an isothermal water bath shaker with initial dye concentration of $50 \mathrm{mg} / \mathrm{L}$. A rapid adsorption can be seen at the initial stage of the contact period. This is most likely due to a large number of surface sites for adsorption. However, it gradually slowed down until it reached equilibrium. After a lap of time, the remaining surface sites are difficult to be occupied because of the repulsion between the solute molecules of the solid and bulk phases. Thus, adsorption took long time to reach equilibrium. Form the Fig. 3, it was found that the contact time is needed for remazol yellow solution with initial concentration of $50 \mathrm{mg} / \mathrm{L}$ to reach equilibrium was $24 \mathrm{~h}$. The maximum percentages removal of Remazol Yellow was found as $82 \%$.

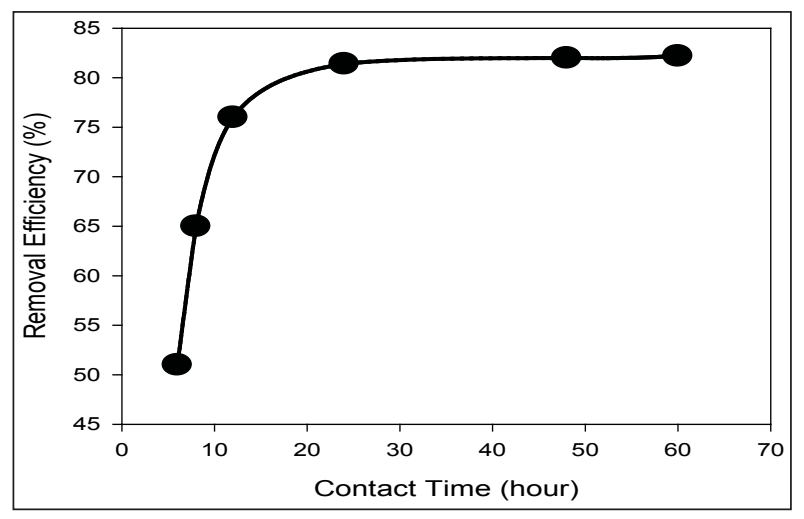

Fig. 3. Effects of contact time on the removal of remazol yellow. Particle size : $140 \mu \mathrm{m}$; Adsorbent amount : $1.0 \mathrm{~g}$; Initial conc.: $\mathbf{5 0} \mathrm{mg} / \mathrm{L}$; Initial volume: $\mathbf{5 0}$ mL; pH: 7.0; Temp.: $25^{\circ} \mathrm{C}$

\section{Effect of $p H$}

The $\mathrm{pH}$ of the dye solution plays an important role in the adsorption capacity, where it affects both the degree of ionization of the dye as well as the surface properties of the adsorbent. In this work, the influence of $\mathrm{pH}$ on the dye adsorption was studied as presented in Fig. 4. The effect of 
$\mathrm{pH}$ on adsorption of dye was studied within $\mathrm{pH}$ range 2-10. The $\mathrm{pH}$ was adjusted by adding a small amount of $0.1 \mathrm{M} \mathrm{HCl}$ and/or $0.1 \mathrm{M} \mathrm{NaOH}$. After $24 \mathrm{~h}$ equilibration at various $\mathrm{pH}$ values illustrated that the percentage adsorption decreased for Remazol Yellow when $\mathrm{pH}$ increased from 2 to 8 (Fig. 4). Thus the $\mathrm{pH}$ value of 2 was selected as the optimum for performing the adsorption studies. The $\mathrm{pH}_{\mathrm{pzc}}$ value of the activated carbon was determined which was 5.5. At lower solution $\mathrm{pH}$ (less than $\mathrm{pH}_{\mathrm{pzc}}$ ), the activated carbon may get positively charged, which enhances the negatively charged reactive dye anions through electrostatic forces of attraction and hence increase the adsorption capacity ${ }^{25}$.

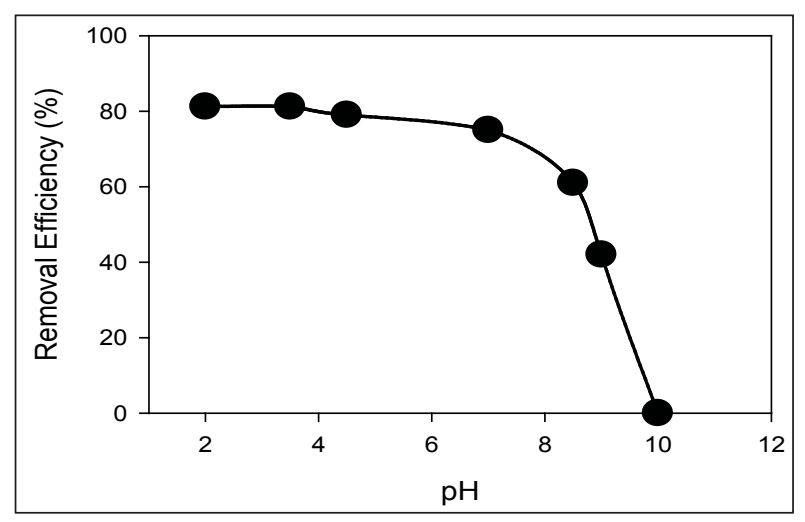

Fig. 4. Effect of pH on the removal of remazol yellow. Particle size : $140 \mu \mathrm{m}$; Adsorbent amount : $1.0 \mathrm{~g}$; Initial conc.: $50 \mathrm{mg} / \mathrm{L}$; Initial volume: $50 \mathrm{~mL}$; Contact time: $24 \mathrm{~h}$; Temp.: $25^{\circ} \mathrm{C}$.

\section{Effect of temperature}

To determine the equilibrium temperature for the maximum uptake of dye solution (Remazol Yellow), the adsorption onto activated carbon was studied for the above optimized condition as a function of temperature $\left(20,30,40\right.$ and $\left.50{ }^{\circ} \mathrm{C}\right)$. A study of the temperature dependence of adsorption process gives valuable information about the enthalpy change during adsorption. Fig. 5 indicates that removal efficiency increases with increasing temperature from $20^{\circ} \mathrm{C}$ to $40^{\circ} \mathrm{C}$. The improvement of adsorption with temperature may be related to an increase in the number of active surface sites available for adsorption on adsorbent, in the porosity, and the total pore volume of the adsorbent. In addition, this can be a result of an increase in their kinetic energy and the enhanced rate of intraparticle diffusion of sorbate with the rise of temperature 28. The results indicated that the adsorption reaction of Remazol Yellow adsorbed by activated carbon prepared from saw dust was an endothermic process in nature.

\section{Effect of various electrolytes}

Reactive dyes are the major cause for complaint. Exhaust reactive dyeing required high salt concentration (up to $80 \mathrm{~g} / \mathrm{L}$ of $\mathrm{Na}_{2} \mathrm{SO}_{4} / \mathrm{NaCl}$ ); salt is added to shift the equilibrium of dye from the aqueous phase to solid (fiber) phase ${ }^{29}$. Thus, effects

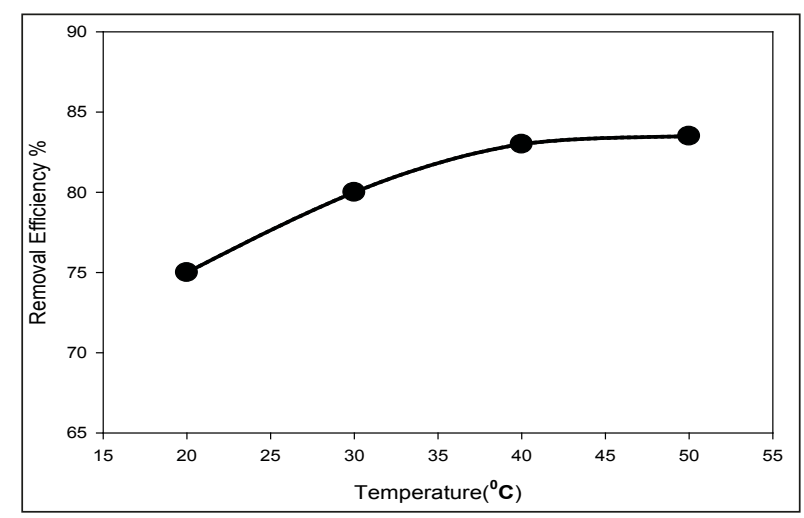

Fig. 5. Effect of Temperature on the removal of remazol yellow. Particle size : $140 \mu \mathrm{m}$; Adsorbent amount : $1.0 \mathrm{~g}$; Initial conc.: $\mathbf{5 0} \mathrm{mg} / \mathrm{L}$; Initial volume: 50 mL ; pH:2; Contact time: 24 hours;

of different electrolytes $\left(\mathrm{NaCl}, \mathrm{KCl}, \mathrm{CaCl}_{2}, \mathrm{AlCl}_{3}\right.$ etc.) on the adsorption kinetics were investigated as shown in Fig. 6. It was found that the addition of these electrolytes to dye solution increased the percentage of dye removal compared to Fig. 5. The colour removal was also dependent on the concentration of added electrolytes. From the Fig. 6, it was found that the removal efficiency gradually decrease with increasing of salt's concentration from $0.01-0.05 \mathrm{M}$. The removal efficiency was highest (94\%) with $0.01 \mathrm{M} \mathrm{NaCl}$ compared to without Salt ( $83 \%$ in Fig. 5). It can be preferred that the salt cations neutralize the negative charge of the carbon surface enabling the adsorption of more molecules or the cations to act directly on the negative adsorbate ion ${ }^{30}$. As seen from the Fig.5, The removal efficiency increases in the order of $\mathrm{NaCl}<\mathrm{KCl}<\mathrm{CaCl}_{2}<\mathrm{AlCl}_{3}$. Removal efficiency decreases as in the case of divalent and trivalent salt. Therefore, considering the cost and efficiency $\mathrm{NaCl}$ is the best electrolyte for the removal of remazol yellow.

\section{Effect of $n a C l$}

From the Fig. 6, it was found that, $\mathrm{NaCl}$ is the best electrolyte for the removal of Remazol Yellow. Presence of $\mathrm{NaCl}$ shows significant effect on removal efficiency of RY, where the removal efficiency was $94 \%$ with $0.01 \mathrm{M} \mathrm{NaCl}$ but without salt it was $84 \%$ (Fig. 7). Here the salt ions force the dye molecule to aggregate and migrate towards the adsorbent surface which increases removal efficiency.

\section{Adsorption isotherm}

The adsorption isotherm used to show the adsorption molecules distribute between the solid phase and liquid phase at adsorption equilibrium state. The Langmuir and Freundlich 


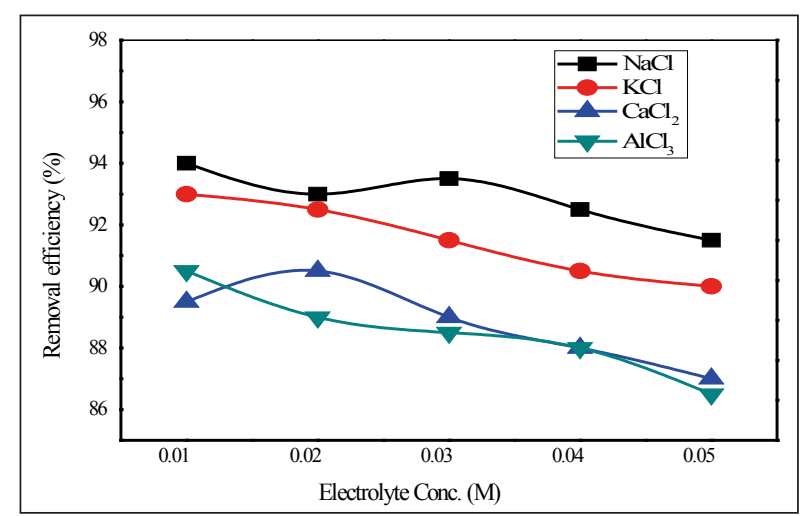

Fig. 6. Effect of various salt on the removal of remazol yellow. Particle size: $140 \mu \mathrm{m}$; Adsorbent amount : 1.0 g; Initial conc.: $50 \mathrm{mg} / \mathrm{L}$; Initial volume: 50 mL ; pH:2;Contact time: 24 h;

isotherms are the most frequently employed models. The linear regression is used to determine the best-fitting isotherm and the pertinency of isotherm equations is compared by evaluating the correlation coefficients, $\mathrm{R}^{2}$. Langmuir's isotherm model is based on the theory that adsorption energy

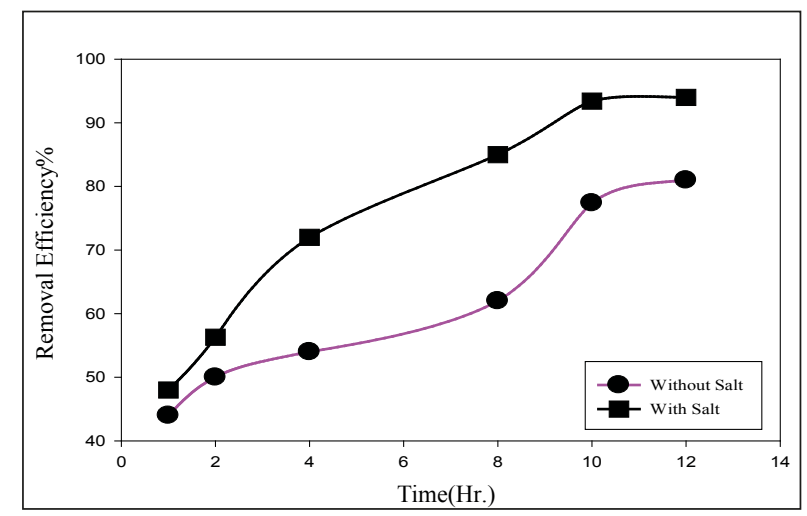

Fig. 6. Effect of various salt on the removal of remazol yellow. Particle size: $140 \mu \mathrm{m}$; Adsorbent amount : 1.0 g; Initial conc.: $50 \mathrm{mg} / \mathrm{L}$; Initial volume: 50 $\mathrm{mL}$; pH:2;Contact time: $24 \mathrm{~h}$;

is constant and uptake occurs on homogeneous surface by monolayer adsorption. When the surface is covered by monolayer of adsorbate, the adsorption goes on localized sites with no interaction between adsorbate molecules and that maximum adsorption occurs ${ }^{31}$. The linear form of Langmuir isotherm equation is given as:

$$
\frac{C_{e}}{q_{e}}=\frac{1}{q_{m} K_{a}}+\frac{C_{e}}{q_{m}}
$$

Where, $\mathrm{C}_{\mathrm{e}}(\mathrm{mg} / \mathrm{L})$ is the equilibrium concentration of remazol yellow and $\mathrm{q}_{\mathrm{e}}(\mathrm{mg} / \mathrm{g})$ is the amount of remazol yellow adsorbed per unit mass of adsorbent. $\mathrm{q}_{\mathrm{m}}(\mathrm{mg} / \mathrm{g})$ is the Langmuir constant related to adsorption capacity and $\mathrm{K}_{\mathrm{a}}$ $(1 / \mathrm{mg})$ is rate of adsorption. The values of $\mathrm{q}_{\mathrm{m}}$ and $\mathrm{K}_{\mathrm{a}}$ were calculated from the intercept and slope of linear plot and are presented in Table I.

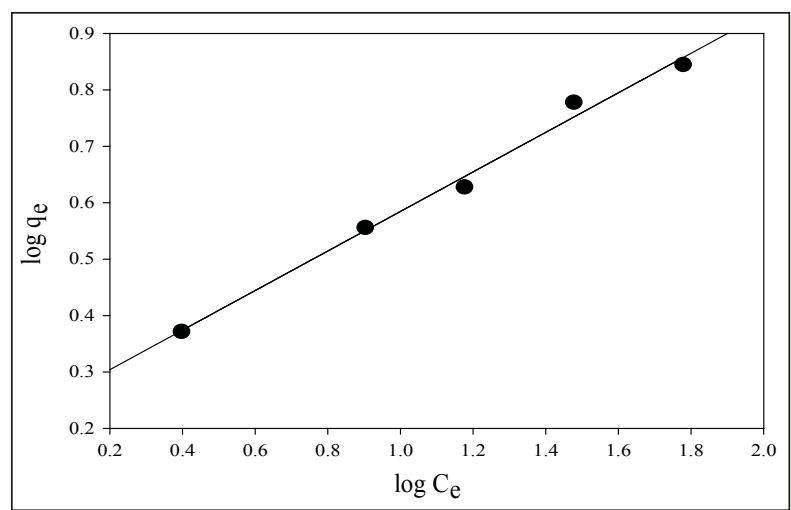

Fig. 8. Freundilch isotherm of remazol yellow

Freundilch model ${ }^{32}$ is an empirical expression that is the earliest known relationship describing the adsorption equation. This isotherm takes into account a heterogeneous surface and multilayer adsorption to the binding sites on the surface of the adsorbent. The Freundlich model is expressed in the following equation:

$$
\log \left(q_{e}\right)=\frac{1}{n} \log \left(C_{e}\right)+\log \left(K_{F}\right)
$$

Where, $\mathrm{K}_{\mathrm{F}}$ and $\mathrm{n}$ are indicative isotherm parameters of adsorption capacity and adsorption intensity, respectively. Generally, $n>1$ illustrates that adsorbate is favorably adsorbed on the adsorbent. The higher of $n$ values favors the adsorption process as well as intensify the adsorption ${ }^{33}$.

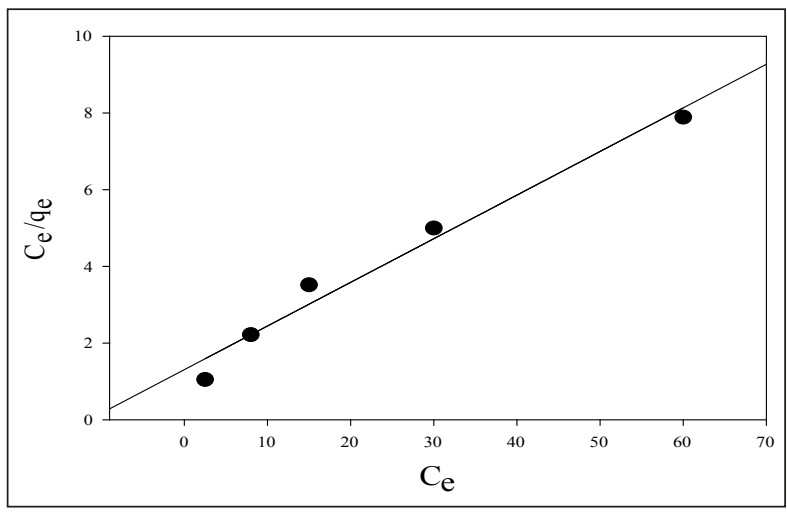

Fig. 9. Langmuir isotherm of remazol yellow 
Table I. Freundlich and Langmuir Parameters and Separation factor $R_{L}$ for Adsorption of RY on treated sawdust.

\begin{tabular}{ccccccccc}
\hline & \multicolumn{3}{c}{ Freundlich isotherm } & \multicolumn{5}{c}{ Langmuir isotherm } \\
\cline { 2 - 8 } & $\mathrm{K}_{\mathrm{F}}$ & $\mathrm{n}$ & $\mathrm{R}^{2}$ & $\mathrm{q}_{\mathrm{m}}$ & $\mathrm{K}_{\mathrm{a}}$ & $\mathrm{R}^{2}$ & $\mathrm{R}_{\mathrm{L}}$ \\
\cline { 2 - 8 } Without Salt & 1.712 & 2.853 & 0.991 & 8.00 & 0.105 & 0.978 & 0.045 \\
With Salt $(\mathrm{NaCl})$ & 1.904 & 4.129 & 0.995 & 5.988 & 0.132 & 0.989 & 0.039 \\
\hline
\end{tabular}

From the Freundilch and Langmuir plot (Fig. 8 and Fig. 9), the isotherm results are presented in Table I. From the Table I, it was found that Freundlich model gave higher $\mathrm{R}^{2}$ values (without salt: 0.991; with salt: 0.995) than Langmuir model (Without salt: 0.978; with salt: 0.989), which indicate that remazol yellow adsorption by activated carbon in presence of electrolyte was made up of heterogeneous surface and multilayer adsorption ${ }^{34}$. This result is similar to other works on reactive dye adsorption by activated carbon prepared from coir pith ${ }^{35}$.

\section{Adsorption kinetics}

Kinetics adsorption data of RY dye on activated charcoal was analyzed using two kinetic models: pseudo-first-order and pseudo-second order. The pseudo-first-order kinetic model is shown by the following equation ${ }^{26}$ :

$$
\log \left(q_{e}-q_{t}\right)=\log q_{e}-\frac{k_{1}}{190 a} t
$$

Where, $\mathrm{q}_{\mathrm{t}}$ is the amount of dye adsorbed at time $\mathrm{t}\left(\mathrm{mgg}^{-1}\right)$, $\mathrm{q}_{\mathrm{e}}$ is the amount adsorbed at equilibrium ( $\left.\mathrm{mg} \mathrm{g}^{-1}\right), \mathrm{k}_{1}$ is the pseudo-first order rate constant $\left(\mathrm{min}^{-1}\right)$ and $\mathrm{t}$ is the contact time ( $\mathrm{min})$.

The values of the constants, $\mathrm{k}_{1}$ and $\mathrm{q}_{\mathrm{e}}$ for the adsorption of dye on the adsorbents were determined from the slopes and intercepts of the plots $\log \left(\mathrm{q}_{\mathrm{e}}-\mathrm{q}_{\mathrm{t}}\right)$ against $\mathrm{t}$, respectively and their values are given in Table III.

Pseudo-second order model can be represented in the following form ${ }^{26}$ :

$$
\frac{t}{q_{t}}=\frac{1}{k_{2}\left(q_{z}\right)^{2}}+\frac{1}{q_{x}} t
$$

Where, $\mathrm{k}_{2}$ is the Pseudo-second order rate constant $\left(\right.$ gmg $\left.^{-1} \mathrm{~min}^{-1}\right)$. The values of the $\mathrm{q}_{\mathrm{e}}$ and $\mathrm{k}_{2}$ were determined by potting a graph between $t / q_{t}$ and time. The applicability of the pseudo first order and pseudo second order model can be examined by linear plot shown in Fig. 10 and 11. The linearity of this plot indicates the applicability of the two models. However the correlation coefficient, $\mathrm{R}^{2}$ shows that second order model fits the experimental data better than the pseudo first order model.

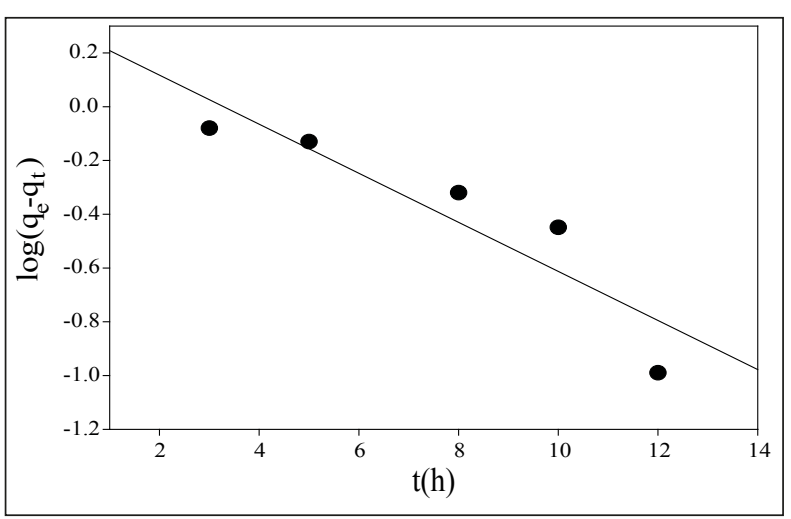

Fig. 10. Pseudo first order Kinetics of remazol yellow

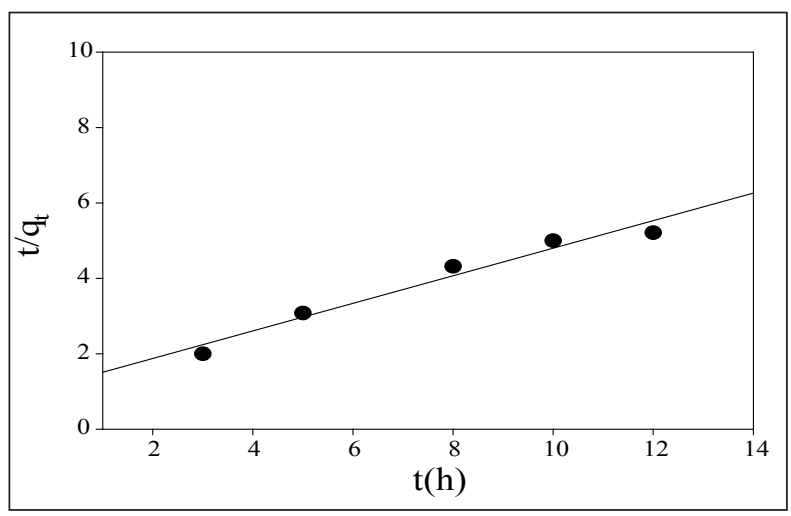

Fig. 11. Pseudo second order Kinetics of remazol yellow 
Table II. Pseudo first order \& second order rate constants, calculated \& experimental $q_{e}$ values for Adsorption of remazol yellow on treated sawdust at $298^{\circ} \mathrm{K}$.

\begin{tabular}{|c|c|c|c|c|c|c|c|}
\hline & \multicolumn{3}{|c|}{ Pseudo first order Kinetic model } & \multirow{2}{*}{$\begin{array}{c}\text { qe exp. } \\
\text { mg/g }\end{array}$} & \multicolumn{3}{|c|}{ Pseudo second order Kinetic model } \\
\hline & $\mathrm{q}_{\mathrm{e}}(\mathrm{mg} / \mathrm{g})$ & $\mathrm{K}_{1}\left(\mathrm{~h}^{-1}\right)$ & $\mathrm{R}^{2}$ & & $\begin{array}{c}\mathrm{q}_{\mathrm{e}} \\
(\mathrm{mg} / \mathrm{g})\end{array}$ & $\begin{array}{c}\mathrm{K}_{2} \\
(\mathrm{~h}, \mathrm{~g} / \mathrm{mg})\end{array}$ & $\mathrm{R}^{2}$ \\
\hline Without Salt & 2.62 & 0.25 & 0.83 & 2.36 & 2.73 & 0.092 & 0.960 \\
\hline $\begin{array}{l}\text { With Salt } \\
(\mathrm{NaCl})\end{array}$ & 3.75 & 0.655 & 0.89 & 2.34 & 2.59 & 0.411 & 0.997 \\
\hline
\end{tabular}

\section{Conclusion}

Activated charcoal produced by chemical activation of saw dust with an activation agent $\mathrm{NaCl}$ was capable of removing Remazol Yellow dye molecules from aqueous solutions. The removal was an adsorption process which was favored at acidic medium with $\mathrm{pH}$ value 2 and adsorption efficiency (removal efficiency) \% was also found to increase with increase in adsorbent dosage, contact time, temperature, and addition of electrolyte. Addition of electrolyte is a new dimension for removal of dye.The kinetic study showed that dye-activated charcoal adsorption systems followed by pseudo-second-order model with high correlation coefficients and the process was endothermic. The equilibrium data was in good agreement with the Langmuir model and dimensionless separation factors $\left(\mathrm{R}_{\mathrm{L}}\right.$ values) within the range of zero to one showed that the adsorption favorable. Therefore, this successful adsorbent could be considered as an alternative to commercial activated charcoal for the removal of Remazol Yellow dye from aqueous solutions.

\section{References}

Asouhidou DD, Triantafyllidis KS, Lazaridis NK and Matis KA (2009), Adsorption of Remazol Red 3BS from aqueous solutions using APTES- and cyclodextrin-modified HMS-type mesoporous silicas, Colloids and Surfaces A, 346(1-3): 83-90.

Ahmad MA and Rahman NK (2011), Equilibrium, kinetics and thermodynamic of Remazol Brilliant Orange 3R dye adsorption on coffee husk-based activated carbon. Chem. Eng. J., 170(1): 154-161.

Ahmad MA and Alrozi R (2011), Optimization of rambutan peel based activated carbon preparation conditions for Remazol Brilliant Blue R removal. Chem. Eng. J., 168 (1): 280-285.
Aksu Z and Isoglu I A (2006), Use of agricultural waste sugar beet pulp for the removal of Gemazol turquoise blue-G reactive dye from aqueous solution, J. Hazard. Mater, 137(1): 418-430.

Amin NK (2008), Removal of reactive dye from aqueous solutions by adsorption onto activated carbons prepared from sugarcane bagasse pith, Desalination, 223(1-3): 152-161.

Ara NJ, Hasan MA, Rahman MA, Salam MA, Salam A and Alam AMS (2013), Removal of Remazol Red from Textile Waste Water Using Treated Sawdust - An Effective Way of Effluent Treatmen, Bangladesh Pharmaceutical J., 16(1): 93-98.

Ahmad MA and Alrozi R (2011), Removal of malachite green dye from aqueous solution using rambutan peel-based activated carbon: Equilibrium, kinetic and thermodynamic studies, Chemical Eng. J., 171(2): 510-516.

Cooper P (1993), Removing colour from dyehouse waste waters - a critical review of technology available. $J$. Soc. Dyers and Colorists, 109(3): 97-100.

Gupta VK, Gupta B, Rastogi A, Agarwal S and Nayak A (2011), A comparative investigation on adsorption performances of mesoporous activated carbon prepared from waste rubber tire and activated carbon for a hazardous azo dye--Acid Blue 113. J. Hazard. Mater. 186(1): 891-901.

Jadhav SB, Phugare SS, Patil PS and Jadhav JP (2011), Biochemical degradation pathway of textile dye Remazol red and subsequent toxicological evaluation by cytotoxicity, genotoxicity and oxidative stress studies. Int. Biodeter. and Biodegrad., 65(6): 733-743.

Qada EN, Allen SJ and Walker GM (2008), Adsorption of 
basic dyes from aqueous solution onto activated carbons. Chem. Eng. J., 135(3): 174-184.

Shen T (1995), Industrial Pollution Prevention, Spring., Berlin, Germany, 95-97.

Luis M, Cotoruelo, Maria. D. Marques and Juan J. Rodriguez. (2007), Adsorption of Aromatic Compounds on Activated Carbons from Lignin: Equilibrium and Thermodynamic Study. Ind. Eng. Chem. Res. 46: 4985.

Dee AK (2006), Environ. Chemistry, New age publication Ltd., India, p 208.

$\mathrm{Hu}$ QH, Qiao SZ and Haghseresht F (2006), Adsorption Study for Removal of Basic Red Dye Using Bentonite, Ind. Eng. Chem. Res. 45: 733.

Srinivasan A and Viraraghavan T (2010), Decolorization of dye wastewaters by biosorbents: A review. J. Environ. Manage. 91(10): 1915-1929.

Banat IM, Nigam P, Singh D and Marchant R (1996), Isolation and Screening of Dye Decolorizing Bacteria. Bioresour. Technol. 58: 217-227.

Konaganti VK, Kota R, Patil S and Madras G (2010), Adsorption of anionic dyes on chitosan grafted poly(alkyl methacrylate)s. Chem. Eng. J. 158(3): 393-401.

Gürses A, Doğar Ç, Karaca S, Açikyildiz M and Bayrak R (2006), Production of granular activated carbon from waste Rosa canina sp. seeds and its adsorption characteristics for dye, J. Hazard. Mater, 131(1-3): 254-259.

Crini G (2006), Non-conventional low-cost adsorbents for dye removal: A review, Bioresour. Technol, 97(9): 1061-1085.

Ramakrishna KR and Viraraghavan T (1997), Dye removal using low cost adsorbents, Water Sci. Technol., 36: (2-3), 189-196.

Gupta VK and Suhas S (2009), Application of low-cost adsorbents for dye removal - A review, J. Environ. Manage. 90(8): 2313-2342.

Santhy K and Selvapathy P (2006), Equilibrium, Kinetics, and Thermodynamics of Remazol, Biores. Technol, 97(11): 1329-1336.

Senthilkumaar S, Kalaamani P, Porkodi K, Varadarajan PR and Subburaam CV (2006), Adsorption of dissolved Reactive red dye from aqueous phase onto activated carbon prepared from agricultural waste, Biores. Technol., 97(14): 1618-1625.
Gupta VK, Mittal A, Malviya A and Mittal J (2009), Adsorption of carmoisine A from wastewater using waste materials-Bottom ash and deoiled soya. $J$. Colloid Interf. Sci., 335(1): 24-33.

Gupta VK, Jain R and Varshney S (2007), Removal of Reactofix golden yellow 3 RFN from aqueous solution using wheat husk-An agricultural waste, J. Hazard. Mater., 142(1-2): 443-448.

Ho YS, Chiu WT and Wang CC (2005), Regression analysis for the sorption isotherms of basic dyes on sugarcane dust, Bioresour. Technol., 96: 1285-1291.

Mohanty K, Naidu JT, Meikap BC and Biswas MN (2006), Removal of Crystal Violet from Wastewater by Activated Carbons Prepared from Rice Husk, Ind. Eng. Chem. Res., 45: 5165-5171.

Dursun AY and Tepe O (2011), Removal of Chemazol Reactive Red 195 from aqueous solution by dehydrated beet pulp carbon, J. Hazard. Mater., 194: 303-311.

Mbolekwa Z and Buckley C (2006), The impact of inadequate wastewater treatment on the receiving water bodies - Case study: Buffalo City and Nkokonbe Municipalities of the Eastern Cape Province, Industrial Wastewater Treatment, WISA, pp 111-112.

Lima EC, Royer B, Vaghetti JCP (2007), Adsorption of $\mathrm{Cu}$ (II) on Araucaria angustifolia wastes: Determination of the optimal conditions by statistic design of experiments, J. Hazard. Mater., 140(1-2): 211-220.

Langmuir I (1918), The adsorption of gases on plane surfaces of glass, mica and platinum, J. Am. Chem. Soci., 40(9): 1361-1403.

Freundlich HMF (1906), J. Physical Chem, 385: 385-470.

Özcan A, Ömeroğlu Č, Erdoğan Y and Özcan AS (2007), Modification of bentonite with a cationic surfactant: An adsorption study of textile dye Reactive Blue 19, J. Hazad. Mater., 140(1-2): 173-179.

Santhy K and Selvapathy P (2006), Removal of reactive dyes from wastewater by adsorption on coir pith activated carbon, Bioresource Technol., 97(11): 1329-1336.

Received: 24 August 2015; Revised: 24 October 2015;

Accepted: 18 December 2015. 